\title{
PREDICTIVE MODEL FOR DETERMINING THE MASS OF BHA AND BHT TO BE ADDED IN COMMERCIAL BIODIESEL
}

\author{
Felipe Y. Savada ${ }^{a}$, Hagata C. Silva ${ }^{\mathrm{a}}$, Ana Carolina G. Mantovani ${ }^{\mathrm{b}}$, Letícia T. Chendynskic, Karina B. Angilellia and Dionísio \\ Borsato $^{\mathrm{a}, *,(1)}$ \\ aDepartamento de Química, Universidade Estadual de Londrina, 86057-970 Londrina - PR, Brasil
}

${ }^{b}$ Departamento de Física, Universidade Estadual de Londrina, 86057-970 Londrina - PR, Brasil

'Instituto Federal do Paraná, Campus Palmas, 85555-000 Palmas - PR, Brasil

Recebido em 16/06/2021; aceito em 31/08/2021; publicado na web em 29/09/2021

\begin{abstract}
Biodiesel is a biofuel produced by the esterification reaction. It is an option to replace fossil fuels, mainly diesel, due to its similar physical and chemical properties. In this research, a mathematical modeling was performed to predict the antioxidant mass to be added in a commercial biodiesel to achieve the minimum oxidative stability provided by the legislation. An equation for each additive was proposed, with the mass of these antioxidants considered as dependent variables and the conformity parameters as independent ones, obtaining multiple regression equations without intercept. The BHA and BHT antioxidants were used. The equations provided were lower at the 5\% level and presented determination coefficients $\left(\mathrm{R}^{2}\right)$ equal to 0.9790 and 0.9770 for the BHA and BHT, respectively, proving their predictability ability and also showing that they can be used to estimate the antioxidant mass to be added in a biodiesel to reach the current regulations.
\end{abstract}

Keywords: antioxidants; mathematical modeling; biodiesel; BHA, BHT.

\section{INTRODUCTION}

The high energy demand and the current environmental problems show the need for renewable energy sources that can bring less impact to the environment. Biodiesel appears as one of the alternatives to replace diesel oil, minimizing dependencies on oil imports and reducing pollution by reducing pollutant gas emissions..$^{1,2}$

The projection of world diesel consumption may reach 5.7 million barrels per day in 2040, according to the Organization of the Petroleum Exporting Countries. ${ }^{3}$ How this will affect our country in the coming years will depend on how the legislation will estimate the addition of biodiesel to ordinary diesel. The consumption of biofuel will raise in conjunction with the increase predicted by OPEC, intensifying the need for research related to biodiesel improvement of production, storage and transportation. ${ }^{4}$

One of the most used methods for the biodiesel synthesis is the alcoholic transesterification with basic catalyst. The synthesis occurs from the reaction of animal fats or vegetable oil with a short chain alcohol, usually methanol, in order to generate esters and glycerol as the final product. The ester produced characterizes biodiesel, thus requiring the removal of other by-products present in the reaction system and the catalyst. 5

In Brazil, in 2018, the three most used raw materials for the biodiesel synthesis were: soybean oil $(67.8 \%)$, tallow (15.6\%) and lard $(2.4 \%)$. The choice is related to its availability, price, climate and the economy of the producing region. ${ }^{6}$

Due to the magnitude of soy plantations in Brazilian soils, it is easy to recognize why this is the main raw material used for biodiesel production. Soy oil has a significant amount of fatty acids with a high unsaturation degree, favorable from the environmental point of view and unfavorable from the technical one, which are incorporated into the biodiesel during the obtention process. These chemical characteristics are undesirable because they favor oxidation and alter the biodiesel quality and its mixtures, making

*e-mail: dborsato@uel.br it difficult to store for long periods due to the reduction of the oxidative stability. ${ }^{7-9}$

The use of vegetable oils as soy can harm the food sector because of the high demand by the biodiesel industry. Therefore, many raw materials, including any viable vegetable oil, frying oil and animal fats, such as tallow, lard and poultry fats, have been widely used in the biodiesel production. ${ }^{10}$

An important factor to be considered is the composition of the raw material used. Soy oil has about $84 \%$ of unsaturated fatty acids as oleic acid, linoleic and linolenic acid. With the variation of the raw material used in the synthesis, the characteristics presented by the product change and consequently the oxidative stability, which is one of the parameters to be respected for the biodiesel commercialization. The oxidation reaction that occurs in the unsaturated carbons of the esters produces free radicals and subproducts that alter their physico-chemical properties. ${ }^{11}$ Mantovani et al.,${ }^{12}$ in their study using spin trapping technique with the electron paramagnetic resonance, evaluated and proved the production of free radicals in biodiesel samples during their storage.

The biodiesel oxidation reaction can be accelerated by exposure to light, heat and the presence of diluted ions or even contact with metals in storage containers. The biodiesel contamination by metal ions has been studied by Chendynski et al.,${ }^{13}$ who evaluated the degradation caused by alloys commonly used in containers as silver steel, carbon steel and copper. Spacino et al., ${ }^{14,15}$ studied the effect of $\mathrm{Fe}^{2+}, \mathrm{Fe}^{3+}$, $\mathrm{Cu}^{2+}, \mathrm{Cr}^{3+}$ and $\mathrm{Co}^{2+}$ ions as catalysts for the biodiesel oxidation reaction. In order to avoid altering the biodiesel characteristics caused by the oxidation reaction, antioxidant molecules capable of reacting with the free radicals formed are added, slowing or inhibiting the oxidation reaction. ${ }^{2}$ Among the antioxidants most used in biodiesel are: butylhydroanisole (BHA), butylhydroxytoluene (BHT) and tertbutylhydroquinone (TBHQ). ${ }^{16,17}$

The current legislations establish the mandatory addition of antioxidants to biodiesel since biodiesel esters are susceptible to the oxidation process. Thus, several authors have used in their researches the addition of antioxidants as BHA and BHT in 
biodiesel. Silva et $a l .,{ }^{18}$ added to biodiesel the antioxidants BHA, BHT and TBHQ, in isolation and in mixtures. The induction period and the relative protection factor were evaluated by the accelerated Rancimat method at temperatures of $110,115,120$ and $125^{\circ} \mathrm{C}$. The study showed that BHA and BHT achieved the minimum oxidative stability parameter at $110^{\circ} \mathrm{C}$, established by the National Petroleum and Biofuels Agency (ANP). ${ }^{19}$

Buosi et al. ${ }^{20}$ applied BHA and BHT in soybean oil biodiesel making a comparison between synthetic antioxidants and natural extracts. The values obtained for the induction period in the Rancimat test at $110^{\circ} \mathrm{C}$, were higher than those established by the Brazilian and European legislation. Maia et al. ${ }^{16}$ studied the effect of BHA and BHT on the rate constant and on the activation energy of the biodiesel oxidation reaction.

The determination of biodiesel physical chemical parameters, such as oxidative stability, flash point, viscosity, specific mass, among others, are important for its commercialization. The knowledge of the biodiesel physical chemical data enables to establish predictive mathematical models that allow to evaluate the effect of the parameters, and to estimate the antioxidant mass to be added to the biodiesel and, thus, to comply with ANP Resolution $\mathrm{n}^{\circ}$ 798, which requires the antioxidant addition in biodiesel. ${ }^{19,21-24}$

The objective of this research was to establish multiple regression equations to estimate the mass of BHA and BHT that must be added to biodiesel, to achieve at least the minimum induction period established by the current legislation.

\section{EXPERIMENTAL PART}

\section{Biodiesel}

Commercial biodiesel samples were supplied by the Fuel Research and Analysis Laboratory of the Department of Chemistry at the State University of Londrina.

\section{Biodiesel physical-chemical characterization.}

The density $\left(20^{\circ} \mathrm{C}\right)$ was determined according to the ASTM D4052 $2^{25}$ method, the flash point by the ASTM D $93,{ }^{26}$ kinematic viscosity $\left(40{ }^{\circ} \mathrm{C}\right)$ by the ASTM D445, ${ }^{27}$ acid number by the ASTM D664,${ }^{28}$ water content by the ASTM D6304,${ }^{29}$ cloud and pour point by the ASTM D2500. ${ }^{30}$

\section{Determination of Induction Period (IP)}

The assays were performed at $110{ }^{\circ} \mathrm{C}$, using the Rancimat equipment (Brand: Metrohm; Model: 873), according to the methodology described in EN 14112. ${ }^{31}$

\section{Antioxidants}

Synthyl butylhydroxyanisole antioxidant (BHA) (98.5\% purity) and Sigma-Aldrich butylhydroxytoluene (BHT) (99.0\% purity), were used. All antioxidants masses were weighted with analytical balance. The additions in biodiesel were made in percentage by mass.

\section{Multiple regression mathematical modeling}

From the physical-chemical parameters of commercial biodiesel samples, the software STATISTICA v.13.132 was used for statistical analysis and mathematical modeling of the equations for each antioxidant. In the modeling, the dependent variable was the antioxidant mass and the independent variables used were: induction period (IP), density (D), flash point (FP), acid number (AN), water content $(\mathrm{W})$, viscosity $(\mathrm{V})$, cloud point $(\mathrm{C})$ and pour point $(\mathrm{P})$.

\section{RESULTS AND DISCUSSION}

Six samples of B100 biodiesel from the Fuel Research and Analysis Laboratory were used. The compliance parameters values, established by the ANP regulation $n^{\circ} 45^{33}$ and $798:{ }^{19}$ induction period with a minimum of 12 hours, density ranging from $850 \mathrm{~kg} \mathrm{~m}^{-3}$ to $900 \mathrm{~kg} \mathrm{~m}^{-3}$, flash point with a minimum value of $100^{\circ} \mathrm{C}$, acid number with a maximum of $0.5 \mathrm{mg}$ of $\mathrm{KOH} \mathrm{g}^{-1}$ of sample, water content with a maximum of $350 \mathrm{mg}$ of water $\mathrm{kg}^{-1}$ of sample, viscosity ranging from $3.0 \mathrm{~mm}^{2} \mathrm{~s}^{-1}$ to $6.0 \mathrm{~mm}^{2} \mathrm{~s}^{-1}$, and cloud point and pour point in ${ }^{\circ} \mathrm{C}$ (minimum values for these parameters are not defined in Brazilian legislation). These data were determined and are shown in Table 1.

The values obtained for the density varied from 879.0 to $881.7 \mathrm{~kg} \mathrm{~m}^{-3}$ of biodiesel. These amounts were within the limits determined by the Brazilian law. The composition of the raw material has a direct effect on the density value because the greater the length of the carbon chain, the lower the density. However, this value will increase with the increase in the unsaturation degree. The presence of impurities as alcohol or adulterants may also influence the biodiesel density. ${ }^{34}$

The flash point values were all above $100{ }^{\circ} \mathrm{C}$, the lower limit described by ANP resolution..$^{33}$ Considering values from $124.8^{\circ} \mathrm{C}$ to $151.5^{\circ} \mathrm{C}$ they exceeded the minimum value required, providing greater security for storage. Comparing with the minimum flash point value of $38^{\circ} \mathrm{C}$ for ordinary diesel, biodiesel has a higher value for this parameter. The increase in the flash point value is seen as beneficial since it is related to the lower temperature at which the application of an ignition source causes the sample vapors to ignite. ${ }^{35}$

The acid number for the six samples was within the limit only for samples 2 and 3, obtaining a value less than or equal to $0.5 \mathrm{mg}$ of $\mathrm{KOH}$ per $\mathrm{g}$ of biodiesel, as required by the Brazilian legislation. ${ }^{33}$ The high acidity of the samples is related to the formation of by-products of the radical oxidation reaction of the biodiesel esters and the low induction periods presented by the samples without antioxidant. ${ }^{36}$

Considering the six samples analyzed, only one was within the limit for water content, being the maximum allowed value for distributors of $350 \mathrm{mg}$ of water per $\mathrm{kg}$ of biodiesel. The water removal from biodiesel is a common and necessary process, to avoid its deposition at the bottom of the storage container and, consequently, to prevent microbial growth that can cause the biodiesel degradation. ${ }^{37}$

The upper and lower limits of the viscosity value at $20^{\circ} \mathrm{C}$ were respected, with samples ranging from 4.063 to $4.504 \mathrm{~mm}^{2} \mathrm{~s}^{-1}$. The viscosity must be within the limits established by the legislation, so that the biofuel does not cause problems in the vehicle's injection system. This parameter is also directly related to the composition of the raw material used to obtain biodiesel, since the lower the number of unsaturations in the carbon chains, the higher the values of the biodiesel kinematic viscosity. ${ }^{38}$

The cloud point $(\mathrm{CP})$ is the temperature that the biodiesel esters start to solidify and separate from the mixture, forming dispersed white solids. The pour point (PP) is the temperature that the product stops flowing. The determination of the cloud points and pour point was carried out and the values obtained varied between $0{ }^{\circ} \mathrm{C}$ to $3{ }^{\circ} \mathrm{C}$ for the cloud point and from $-4^{\circ} \mathrm{C}$ to $2^{\circ} \mathrm{C}$ for the pour point. In regions that can reach lower temperatures, it is important that these values are lower so that freezing solidification does not occur during storage or in the vehicle tank, which can cause problems in the injection system. ${ }^{39}$ The cloud and pour point are directly related to the type of raw material used. Tallow produces biodiesel with higher $\mathrm{CP}$ and $\mathrm{PP}$, and soybean oil, with more unsaturation, reduces the value of these parameters. ${ }^{7,10}$ 
For the oxidation stability test at $110^{\circ} \mathrm{C}$, none of the samples reached the minimum value of 12 hours established by the Brazilian legislation. ${ }^{19}$ According to Table 1 , the sample 4 presented the shortest induction period, with a value of 1.35 hours. The highest value found for oxidation stability was $4.98 \mathrm{~h}$, much lower than the minimum value established. These values are also not within the limits for the European standard, which establishes a minimum of 8 hours. ${ }^{40}$

The samples were mixed with the antioxidants and oxidation stability tests were performed on the Rancimat ${ }^{\circledR}$ equipment. The data of the physico-chemical parameters and the BHA mass added to the biodiesel are shown in Table 1 .

For the BHA antioxidant the lowest mass required to reach values close to twelve hours was $0.5 \%$ for samples 1 and 5 . It can be seen that the antioxidant effect offered is different, depending on the sample's composition.

Sample 3 did not reach values close to 12 hours nor in the greatest addition of antioxidants. In these cases, the antioxidant offers little protection against the unsaturation present in the ester chains, normally associated with the biodiesel oxidation that occurred previously.

After mixing the biodiesel samples with BHT, oxidation stability tests were performed on Rancimat ${ }^{\circledR}$ equipment. The data of the physico-chemical parameters and the mass of BHT added to the biodiesel are presented in Table 2 .

For the BHT antioxidant, values close to, or greater than, the minimum of 12 hours required for five of the six samples analyzed were achieved. For the values obtained from the induction period, sample 4 was the only one that did not reach the minimum value for BHT. We must take into account the mathematical approximation that should be applied to the IP values of samples 3, 5 and 6 that presented IP of 11.82, 11.63 and 11.61 hours that, by approximation, could be considered equal to 12 hours. Despite the similarity of the added masses, the protection offered varies according to the antioxidants used. Therefore, the antioxidant selection must follow technical criteria and must consider the characteristics of each biodiesel sample.

Table 1. BHA concentration (\%) and values of the physico-chemical parameters analyzed for each biodiesel sample in the absence and presence of the antioxidant

\begin{tabular}{|c|c|c|c|c|c|c|c|c|c|}
\hline Sample & $\begin{array}{c}\text { BHA } \\
(\%)\end{array}$ & $\begin{array}{l}\text { IP } \\
\text { (h) }\end{array}$ & $\begin{array}{c}\mathrm{D} \\
\left(\mathrm{kg} \mathrm{m}^{-3}\right)\end{array}$ & $\begin{array}{l}\mathrm{FP} \\
\left({ }^{\circ} \mathrm{C}\right)\end{array}$ & $\begin{array}{c}\mathrm{AN} \\
\left(\mathrm{mgKOH} \mathrm{g}^{-1}\right)\end{array}$ & $\begin{array}{c}\mathrm{W} \\
\left(\mathrm{mg} \mathrm{kg}^{-1}\right)\end{array}$ & $\begin{array}{c}\mathrm{V} \\
\left(\mathrm{mm}^{2} \mathrm{~s}^{-1}\right)\end{array}$ & $\begin{array}{c}\mathrm{C} \\
\left({ }^{\circ} \mathrm{C}\right)\end{array}$ & $\begin{array}{c}\mathrm{P} \\
\left({ }^{\circ} \mathrm{C}\right)\end{array}$ \\
\hline \multirow{4}{*}{1} & 0.00 & 1.82 & 881.7 & 126.5 & 0.78 & 394.2 & 4.169 & 1 & -3 \\
\hline & 0.30 & 8.94 & 881.7 & 126.5 & 0.78 & 394.2 & 4.169 & 1 & -3 \\
\hline & 0.40 & 9.95 & 881.7 & 126.5 & 0.78 & 394.2 & 4.169 & 1 & -3 \\
\hline & 0.50 & 11.69 & 881.7 & 126.5 & 0.78 & 394.2 & 4.169 & 1 & -3 \\
\hline \multirow{7}{*}{2} & 0.00 & 2.62 & 879.9 & 124.8 & 0.405 & 365.9 & 4.504 & 0 & -4 \\
\hline & 0.10 & 6.03 & 879.9 & 124.8 & 0.405 & 365.9 & 4.504 & 0 & -4 \\
\hline & 0.15 & 6.17 & 879.9 & 124.8 & 0.405 & 365.9 & 4.504 & 0 & -4 \\
\hline & 0.20 & 7.54 & 879.9 & 124.8 & 0.405 & 365.9 & 4.504 & 0 & -4 \\
\hline & 0.40 & 10.16 & 879.9 & 124.8 & 0.405 & 365.9 & 4.504 & 0 & -4 \\
\hline & 0.45 & 10.96 & 879.9 & 124.8 & 0.405 & 365.9 & 4.504 & 0 & -4 \\
\hline & 0.60 & 13.36 & 879.9 & 124.8 & 0.405 & 365.9 & 4.504 & 0 & -4 \\
\hline \multirow{4}{*}{3} & 0.00 & 3.48 & 880.6 & 131.8 & 0.500 & 365.7 & 4.063 & 0 & -4 \\
\hline & 0.40 & 7.69 & 880.6 & 131.8 & 0.500 & 365.7 & 4.063 & 0 & -4 \\
\hline & 0.45 & 7.99 & 880.6 & 131.8 & 0.500 & 365.7 & 4.063 & 0 & -4 \\
\hline & 0.50 & 8.30 & 880.6 & 131.8 & 0.500 & 365.7 & 4.063 & 0 & -4 \\
\hline \multirow{6}{*}{4} & 0.00 & 1.35 & 880.8 & 151.5 & 0.750 & 386.2 & 4.161 & 1 & -2 \\
\hline & 0.20 & 4.44 & 880.8 & 151.5 & 0.750 & 386.2 & 4.161 & 1 & -2 \\
\hline & 0.45 & 7.37 & 880.8 & 151.5 & 0.750 & 386.2 & 4.161 & 1 & -2 \\
\hline & 0.50 & 7.39 & 880.8 & 151.5 & 0.750 & 386.2 & 4.161 & 1 & -2 \\
\hline & 0.60 & 8.38 & 880.8 & 151.5 & 0.750 & 386.2 & 4.161 & 1 & -2 \\
\hline & 1.00 & 12.31 & 880.8 & 151.5 & 0.750 & 386.2 & 4.161 & 1 & -2 \\
\hline \multirow{6}{*}{5} & 0.00 & 4.98 & 879.0 & 146.8 & 0.840 & 278.8 & 4.216 & 2 & -3 \\
\hline & 0.15 & 7.53 & 879.0 & 146.8 & 0.840 & 278.8 & 4.216 & 2 & -3 \\
\hline & 0.30 & 9.74 & 879.0 & 146.8 & 0.840 & 278.8 & 4.216 & 2 & -3 \\
\hline & 0.45 & 11.2 & 879.0 & 146.8 & 0.840 & 278.8 & 4.216 & 2 & -3 \\
\hline & 0.50 & 11.81 & 879.0 & 146.8 & 0.840 & 278.8 & 4.216 & 2 & -3 \\
\hline & 0.60 & 13.04 & 879.0 & 146.8 & 0.840 & 278.8 & 4.216 & 2 & -3 \\
\hline \multirow{6}{*}{6} & 0.00 & 2.64 & 880.3 & 133.7 & 0.550 & 399.4 & 4.126 & 3 & -2 \\
\hline & 0.15 & 6.64 & 880.3 & 133.7 & 0.550 & 399.4 & 4.126 & 3 & -2 \\
\hline & 0.30 & 8.67 & 880.3 & 133.7 & 0.550 & 399.4 & 4.126 & 3 & -2 \\
\hline & 0.40 & 10.26 & 880.3 & 133.7 & 0.550 & 399.4 & 4.126 & 3 & -2 \\
\hline & 0.45 & 10.71 & 880.3 & 133.7 & 0.550 & 399.4 & 4.126 & 3 & -2 \\
\hline & 0.60 & 12.74 & 880.3 & 133.7 & 0.550 & 399.4 & 4.126 & 3 & -2 \\
\hline
\end{tabular}


Table 2. BHT concentration (\%) and values of the physico-chemical parameters analyzed for each biodiesel sample in the absence and presence of the antioxidant

\begin{tabular}{|c|c|c|c|c|c|c|c|c|c|}
\hline Sample & $\begin{array}{c}\text { BHT } \\
(\%)\end{array}$ & $\begin{array}{l}\text { IP } \\
(\mathrm{h})\end{array}$ & $\begin{array}{c}\mathrm{D} \\
\left(\mathrm{kg} \mathrm{m}^{-3}\right)\end{array}$ & $\begin{array}{l}\text { FP } \\
\left({ }^{\circ} \mathrm{C}\right)\end{array}$ & $\begin{array}{c}\mathrm{AN} \\
\left(\mathrm{mgKOH} \mathrm{g}^{-1}\right)\end{array}$ & $\begin{array}{c}\mathrm{W} \\
\left(\mathrm{mg} \mathrm{kg}^{-1}\right) \\
\end{array}$ & $\begin{array}{c}\mathrm{V} \\
\left(\mathrm{mm}^{2} \mathrm{~s}^{-1}\right)\end{array}$ & $\begin{array}{c}\mathrm{C} \\
\left({ }^{\circ} \mathrm{C}\right) \\
\end{array}$ & $\begin{array}{c}\mathrm{P} \\
\left({ }^{\circ} \mathrm{C}\right) \\
\end{array}$ \\
\hline \multirow[t]{10}{*}{1} & 0.00 & 1.82 & 881.7 & 126.5 & 0.780 & 394.2 & 4.169 & 1 & -3 \\
\hline & 0.15 & 5.1 & 881.7 & 126.5 & 0.780 & 394.2 & 4.169 & 1 & -3 \\
\hline & 0.20 & 5.46 & 881.7 & 126.5 & 0.780 & 394.2 & 4.169 & 1 & -3 \\
\hline & 0.30 & 7.36 & 881.7 & 126.5 & 0.780 & 394.2 & 4.169 & 1 & -3 \\
\hline & 0.35 & 7.76 & 881.7 & 126.5 & 0.780 & 394.2 & 4.169 & 1 & -3 \\
\hline & 0.40 & 8.53 & 881.7 & 126.5 & 0.780 & 394.2 & 4.169 & 1 & -3 \\
\hline & 0.45 & 9.63 & 881.7 & 126.5 & 0.780 & 394.2 & 4.169 & 1 & -3 \\
\hline & 0.50 & 10.06 & 881.7 & 126.5 & 0.780 & 394.2 & 4.169 & 1 & -3 \\
\hline & 0.60 & 11.06 & 881.7 & 126.5 & 0.780 & 394.2 & 4.169 & 1 & -3 \\
\hline & 0.70 & 13.13 & 881.7 & 126.5 & 0.780 & 394.2 & 4.169 & 1 & -3 \\
\hline \multirow[t]{9}{*}{2} & 0.00 & 2.62 & 879.9 & 124.8 & 0.405 & 365.9 & 4.504 & 0 & -4 \\
\hline & 0.15 & 5.31 & 879.9 & 124.8 & 0.405 & 365.9 & 4.504 & 0 & -4 \\
\hline & 0.20 & 6.29 & 879.9 & 124.8 & 0.405 & 365.9 & 4.504 & 0 & -4 \\
\hline & 0.30 & 7.82 & 879.9 & 124.8 & 0.405 & 365.9 & 4.504 & 0 & -4 \\
\hline & 0.35 & 8.62 & 879.9 & 124.8 & 0.405 & 365.9 & 4.504 & 0 & -4 \\
\hline & 0.40 & 9.44 & 879.9 & 124.8 & 0.405 & 365.9 & 4.504 & 0 & -4 \\
\hline & 0.45 & 10.27 & 879.9 & 124.8 & 0.405 & 365.9 & 4.504 & 0 & -4 \\
\hline & 0.50 & 10.99 & 879.9 & 124.8 & 0.405 & 365.9 & 4.504 & 0 & -4 \\
\hline & 0.60 & 12.75 & 879.9 & 124.8 & 0.405 & 365.9 & 4.504 & 0 & -4 \\
\hline \multirow[t]{8}{*}{3} & 0.00 & 3.48 & 880.6 & 131.8 & 0.500 & 365.7 & 4.063 & 0 & -4 \\
\hline & 0.30 & 7.62 & 880.6 & 131.8 & 0.500 & 365.7 & 4.063 & 0 & -4 \\
\hline & 0.35 & 8.03 & 880.6 & 131.8 & 0.500 & 365.7 & 4.063 & 0 & -4 \\
\hline & 0.40 & 8.57 & 880.6 & 131.8 & 0.500 & 365.7 & 4.063 & 0 & -4 \\
\hline & 0.45 & 9.11 & 880.6 & 131.8 & 0.500 & 365.7 & 4.063 & 0 & -4 \\
\hline & 0.50 & 9.65 & 880.6 & 131.8 & 0.500 & 365.7 & 4.063 & 0 & -4 \\
\hline & 0.60 & 10.36 & 880.6 & 131.8 & 0.500 & 365.7 & 4.063 & 0 & -4 \\
\hline & 0.70 & 11.82 & 880.6 & 131.8 & 0.500 & 365.7 & 4.063 & 0 & -4 \\
\hline \multirow[t]{7}{*}{4} & 0.00 & 1.35 & 880.8 & 151.5 & 0.750 & 386.2 & 4.161 & 1 & -2 \\
\hline & 0.35 & 3.77 & 880.8 & 151.5 & 0.750 & 386.2 & 4.161 & 1 & -2 \\
\hline & 0.40 & 4.06 & 880.8 & 151.5 & 0.750 & 386.2 & 4.161 & 1 & -2 \\
\hline & 0.45 & 4.54 & 880.8 & 151.5 & 0.750 & 386.2 & 4.161 & 1 & -2 \\
\hline & 0.50 & 4.63 & 880.8 & 151.5 & 0.750 & 386.2 & 4.161 & 1 & -2 \\
\hline & 0.60 & 5.21 & 880.8 & 151.5 & 0.750 & 386.2 & 4.161 & 1 & -2 \\
\hline & 0.70 & 5.41 & 880.8 & 151.5 & 0.750 & 386.2 & 4.161 & 1 & -2 \\
\hline \multirow[t]{6}{*}{5} & 0.00 & 4.98 & 879.0 & 146.8 & 0.840 & 278.8 & 4.216 & 2 & -3 \\
\hline & 0.10 & 7.69 & 879.0 & 146.8 & 0.840 & 278.8 & 4.216 & 2 & -3 \\
\hline & 0.15 & 8.1 & 879.0 & 146.8 & 0.840 & 278.8 & 4.216 & 2 & -3 \\
\hline & 0.30 & 10.49 & 879.0 & 146.8 & 0.840 & 278.8 & 4.216 & 2 & -3 \\
\hline & 0.35 & 11.32 & 879.0 & 146.8 & 0.840 & 278.8 & 4.216 & 2 & -3 \\
\hline & 0.40 & 11.63 & 879.0 & 146.8 & 0.840 & 278.8 & 4.216 & 2 & -3 \\
\hline \multirow[t]{4}{*}{6} & 0.00 & 2.64 & 880.3 & 133.7 & 0.550 & 399.4 & 4.126 & 3 & -2 \\
\hline & 0.30 & 9.49 & 880.3 & 133.7 & 0.550 & 399.4 & 4.126 & 3 & -2 \\
\hline & 0.35 & 9.69 & 880.3 & 133.7 & 0.550 & 399.4 & 4.126 & 3 & -2 \\
\hline & 0.40 & 11.61 & 880.3 & 133.7 & 0.550 & 399.4 & 4.126 & 3 & -2 \\
\hline
\end{tabular}

In order to determine the antioxidant mass that should be added to biodiesel, the data in Tables 1 and 2 were tabulated and inserted in the multiple regression module, from the Statistica v.13.1 application, ${ }^{32}$ to obtain a predictive mathematical model.

A multiple regression equation, without intercept, was obtained to estimate the percentage by mass of each antioxidant employed. The dependent variable (target) was considered the antioxidant mass and the induction period values and the other parameters used in Tables 1 and 2 were considered as independent variables.

The equation 1 was obtained by multiple regression of the parameter values presented in Table 1. It estimates the mass of BHA to be added to biodiesel, depending on the independent variables: 
induction period, pour point, cloud point, water content, viscosity, density and acid number. The parameters viscosity, density and acid number with an asterisk because they are not significant, at the 5\% level. The $\mathrm{P}$ coefficient was equal to zero, indicating that the influence of this parameter in the estimation of BHA mass is null.

$\% \mathrm{BHA}=0.0686 \mathrm{IP}+0.010 \mathrm{FP}-0.0669 \mathrm{C}+0.0018 \mathrm{~W}-0.2107 \mathrm{~V} *$ $0.0014 \mathrm{D}^{*}-0.1011 \mathrm{AN}^{*}+0.0 \mathrm{P}$

The Pareto diagram (Figure 1) shows the most significant variables in the model, with the values positioned to the right of the red line being significant and refer to the t-statistic. The further to the right the variable is, the greater its importance in the model.

According to the Pareto diagram (Figure 1), the mathematical model of the BHA has as its most significant term the induction period followed by the flash point, cloud point, water content, viscosity, density and acid number. It is observed in equation 1 that the increase in IP, FP and W cause an increase in the BHA mass, and an increase in $\mathrm{C}, \mathrm{V}, \mathrm{D}$ and $\mathrm{AN}$ cause an antagonistic effect.

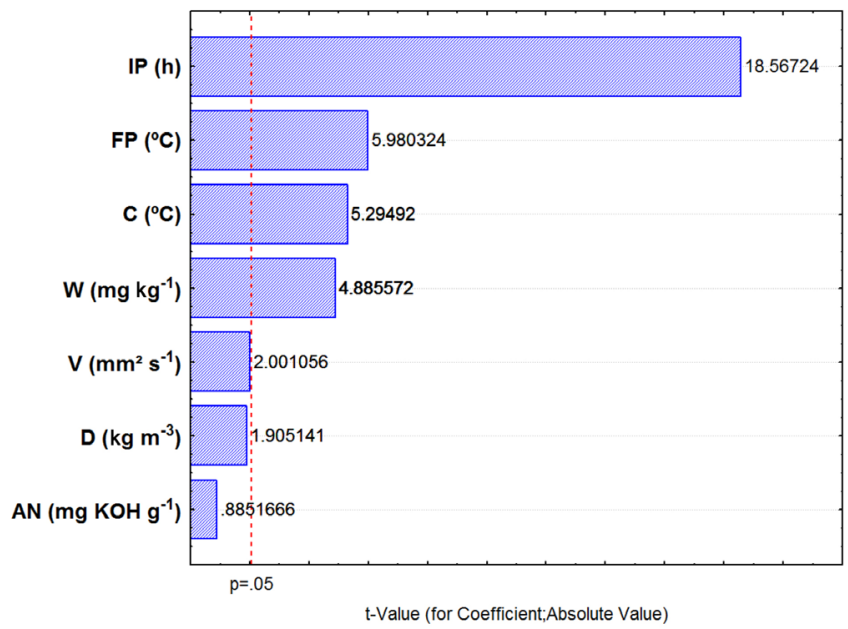

Figure 1. Pareto diagram for the BHA mass equation

The highest significance degree attributed to the variable IP demonstrates the importance of this term to determine the antioxidant mass. The smaller impacts of the other variables only demonstrate their lower contribution to the final value of the mass, but with 3 of them, within the limit to be considered significant. The parameters viscosity $(p=0.056)$, density $(p=0.070)$ and acid number $(p=0.380)$, contribute negatively, which would be desirable, as they cause a reduction in the BHA mass. However, they do not contribute significantly, presenting less impact on the final mass value of the BHA antioxidant, especially AN.

The data of the mixtures with the antioxidant BHT, present in Table 2, were tabulated and presented to the multiple regression module of the software Statistica v.13.1.32 The multiple regression equation obtained, without intercept, containing the eight independent variables is shown in equation 2 , where the dependent variable represents the mass percentage of BHT. The asterisk term indicates that it is not significant at the $5 \%$ level. The $\mathrm{P}$ coefficient was equal to zero showing that the influence of this parameter in the BHT mass estimation is null.

$\% \mathrm{BHT}=0.0665 \mathrm{IP}+0.0037 \mathrm{~W}+0.0141 \mathrm{FP}-0.1021 \mathrm{C}-0.0045 \mathrm{D}+$ $0.1949 \mathrm{AN}+0.1168 \mathrm{~V}^{*}+0.00 \mathrm{P}$

Figure 2 contains the Pareto diagram, which shows the most significant variables in the mathematical model obtained.

The mathematical model that estimates the mass of BHT (Eq. 2), according to the Pareto graph (Figure 2), has as its most significant term the induction period followed by the water content, flash point, cloud point, density, acid number and viscosity. In equation 2 , the increase in IP, W, FP, AN and V causes an increase in the BHT mass, and the increase in $\mathrm{C}$ and $\mathrm{D}$ causes an opposite effect on the mass of BHT.

A difference between equations 1 and 2 is the positive collaboration of the viscosity parameter for BHT and negative one for BHA. Differently for each antioxidant, samples that present higher viscosity will need a lower addition of BHA to reach the same IP when compared to BHT. The same is true for AN comparing the two antioxidants.

The Pareto diagram for the BHT model (Figure 2) presents six significant parameters at the $5 \%$ level.

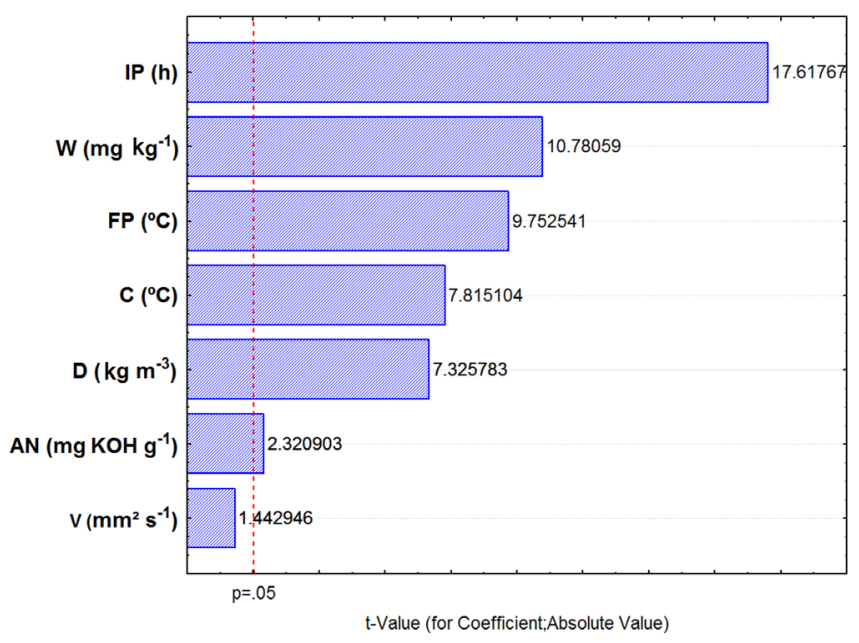

Figure 2. Pareto diagram for the BHT mass equation

The IP variable again has the greatest impact to define the antioxidant mass in the model with the highest value for the t-test.

The obtained equations presented determination coefficient values of $\left(\mathrm{R}^{2}\right) 0.9790$ and 0.9770 for BHA and BHT, respectively. The p-value was $1 \times 10^{-5}$ for both models. The $t$ test for the complete equation demonstrated that they are significant for describing the antioxidant mass.

Figures 3 and 4 describe the response surfaces for the parameters used in the modeling using BHA and BHT. The antioxidant mass used is directly related to the induction period, thus, these variables were represented in all response surfaces. The antioxidant mass is displayed in the perpendicular axis and in the induction period and the other variables are shown in the two-dimensional plane, in order to evaluate the influence of each of them in the responses.

Shieh and collaborators ${ }^{41}$ applied second order polynomial regressions in samples of oils used for biodiesel synthesis. Response surfaces were obtained for the data in different temperatures, reaction time and reagents proportions. The response surfaces obtained allowed to define the parameters that most influenced the biodiesel synthesis.

The response surface figures show a three-dimensional contour region with its projection on a two-dimensional plane. The values of the adjusted surface, in terms of the response variable, can be represented by lines of various color shades in a graph containing two independent variables, which must be chosen according to their degree of importance in the model or another specific reason. Beside the graph we have the response of the dependent variable. ${ }^{42}$ 
The study of response surfaces can assist in determining the antioxidant mass to be added to biodiesel. The selection of the antioxidant goes beyond the protection effect by mass used, it also involves its solubility, storage time, toxicity and even yield in low concentrations. As the raw material used in the production of biodiesel varies according to the region in which it is produced, specific studies are necessary because, in some cases, low-cost raw materials are used, such as frying oil and, even materials with a high content of free fatty acids. ${ }^{43}$

Figure 3 contains the five response surfaces for the BHA data. The response surface for the density was not included since no relevant relationship was found with this variable.

Figure 3 relates the BHA mass with the induction period and the flash point. In order to minimize the antioxidant mass and achieve an induction period of 8 hours ${ }^{40}$ or 12 hours $^{19}$ the biodiesel flash point should be between 135 and $145^{\circ} \mathrm{C}$. For FP values, outside this range, we need a greater amount of BHA.

Shahabuddin and collaborators ${ }^{44}$ studied the effect of storage in palm oil biodiesel, jatropha oil, coconut fat and mixtures with
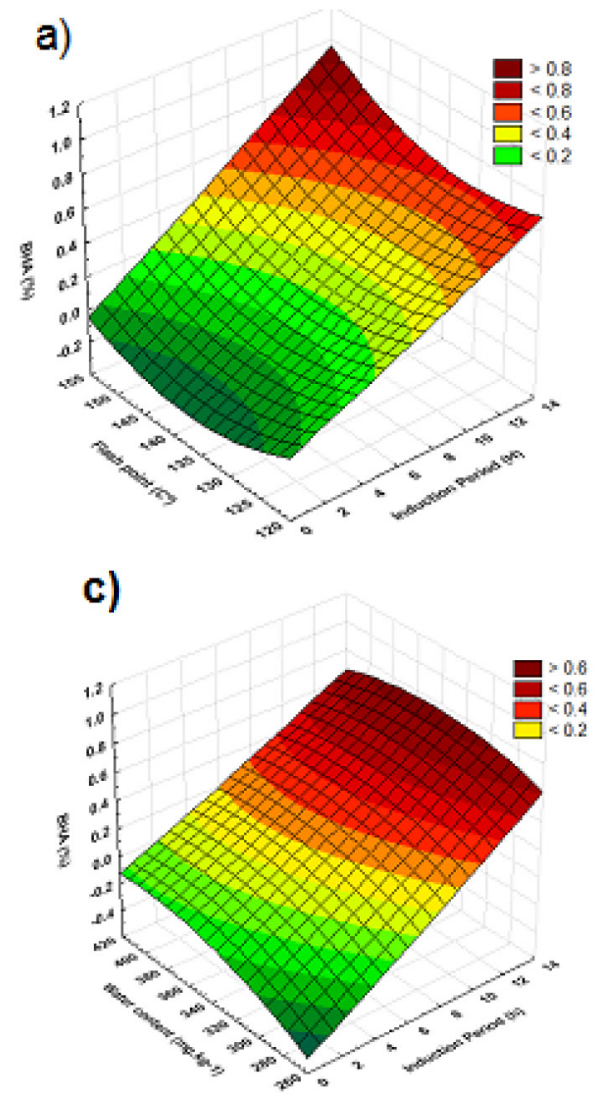

petroleum diesel. They found a $30{ }^{\circ} \mathrm{C}$ reduction in FP in samples after 3 months of storage.

Figure $3 \mathrm{~b}$ shows the behavior of $\mathrm{C}$ in relation to the BHA mass and the induction period. We can see that this variable does not have much influence on the antioxidant mass ratio and induction period. The smallest mass of BHA, necessary to reach IP values, which comply with the legislation, is located at the lower and upper end of the $C$ values (Figure $3 b$ ). The cloud and pour point value are related to the presence of double bonds in the esters because the greater the number of double bonds, lower are the $\mathrm{C}$ and $\mathrm{P}$ values. ${ }^{45}$ Therefore, the raw material choice to produce biodiesel influences these parameters' behavior.

The response surface contained in Figure $3 \mathrm{c}$ relates the parameter $\mathrm{W}$ with IP and the percentage of BHA antioxidant mass. The surface behavior describes that lower values of $\mathrm{W}$ present lower additions of BHA to reach IP values that meet the legislation. An option to reduce the antioxidant mass to be added would be to reduce the biodiesel water content by vacuum drying. ${ }^{46} \mathrm{New}$ water withdrawal technologies have been used, such as the addition of hydrogel, which are products that have an affinity for water. ${ }^{47}$
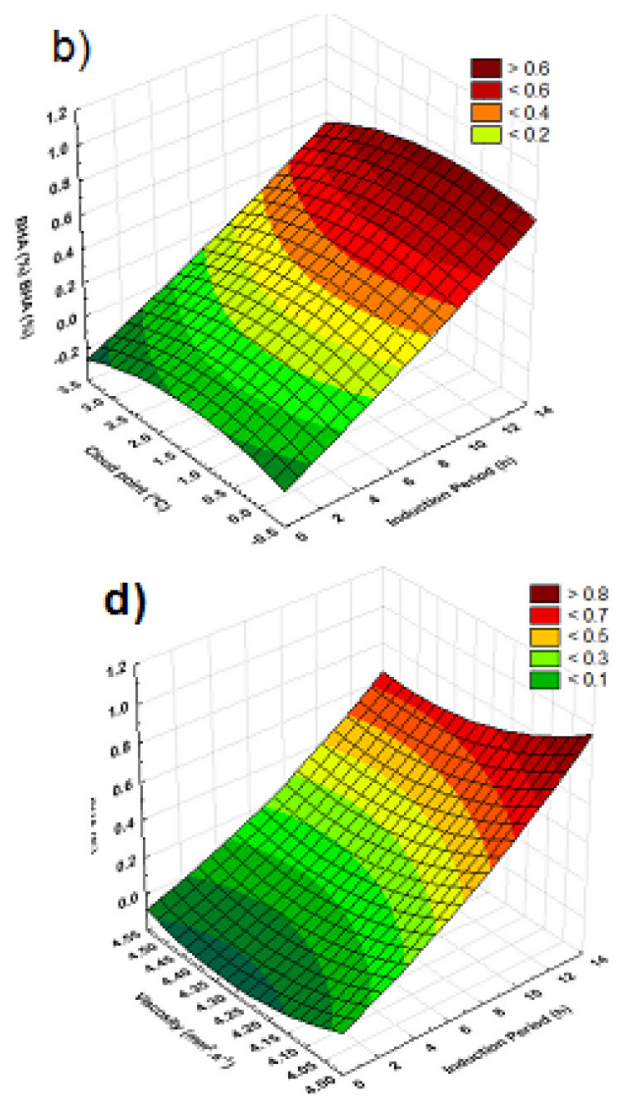

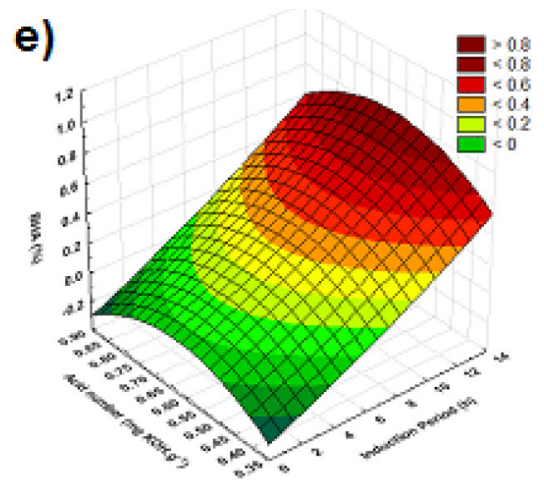

Figure 3. Response surfaces relating the BHA mass and induction period with flash point (a), cloud point (b), water content (c), viscosity (d) and acid number (e) 
Figure $3 \mathrm{~d}$ shows a similar behavior to that seen in Figure 3a, however, the higher the biodiesel viscosity, the lower is the BHA mass to reach the IP value of 8 or 12 hours.

The response surface shown in Figure 3e relates the parameter AN with IP and the percentage by mass of the BHA antioxidant. The surface behavior describes that lower values of AN present lower additions of BHA to reach IP values that meet the legislation.

Figure 4 contains the five response surfaces related to the BHT antioxidant mass with the induction period and the other independent variables. The response surface for the density was not included, as no relevant relationship was found with this variable.

The response surface for the effect of $\mathrm{W}$ is presented in Figure 4a. It has a similar behavior to the BHA, showing that the lower the water content, the lower the antioxidant mass to reach an IP value of at least $12 \mathrm{~h}$.

For the FP (Figure 4b), the region that presents the best protection by the antioxidant occurs for intermediate values of this parameter. The same behavior can be observed for BHA (Figure 3a). Similar but more accentuated behavior than the one observed in Figure $3 \mathrm{~b}$ can be seen in Figure 4c. It shows that the lower the cloud point, the lower the antioxidant mass to reach an IP value that meets both Brazilian and European legislation.

According to Figure 4d, the lower the acidity content $(0.35$ to $0.50 \mathrm{mg}_{\text {Кон }} \mathrm{g}^{-1}$ ), the lower the necessary BHT mass to meet the standards regarding IP. Values above the law, due to sample nonconformity, if they were above $0.5 \mathrm{mg}_{\mathrm{KOH}} \mathrm{g}^{-1}$ of biodiesel, were not considered in the model optimization.

According to Figure $4 \mathrm{e}$, for intermediate viscosity values $(4.25$ to $4.35 \mathrm{~mm}^{2} \mathrm{~s}^{-1}$ ), less BHT mass will be necessary to reach a longer induction period meeting the established norms.

Figures 5 and 6 contain the optimization profiles of the antioxidant mass to be used and the independent variables values, obtained from equations 1 and 2, for each antioxidant. The optimization allows the definition of parameter values, taking into account the compliance limits of all variables involved, minimizing the antioxidant.

The BHA optimization correlating all variables involved is shown in Figure 5. The optimization shows that the smallest BHA
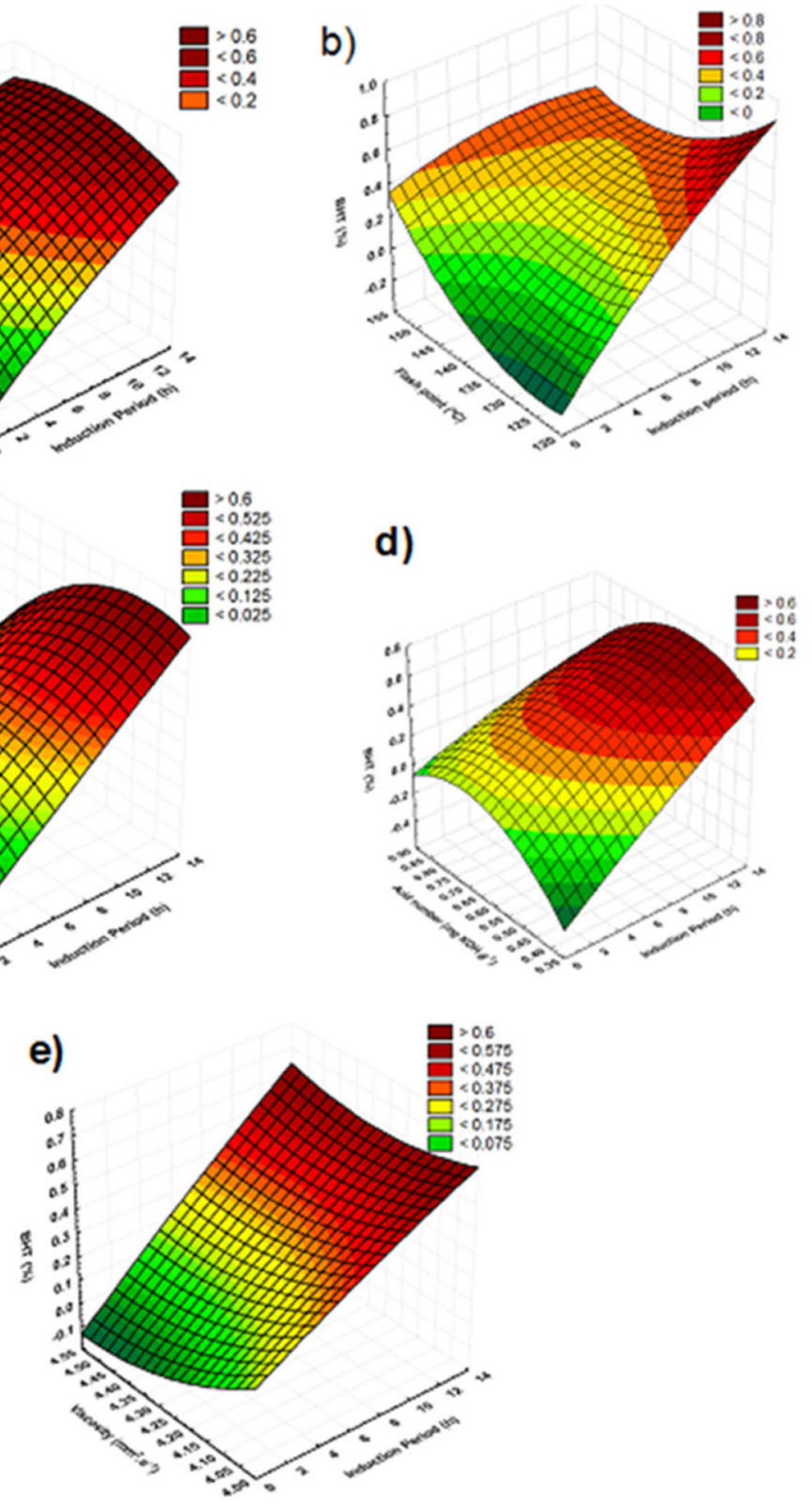

Figure 4. Response surfaces relating the BHT mass and induction period with water content (a), flash point (b), cloud point (c), acid number (d) and viscosity (e) 


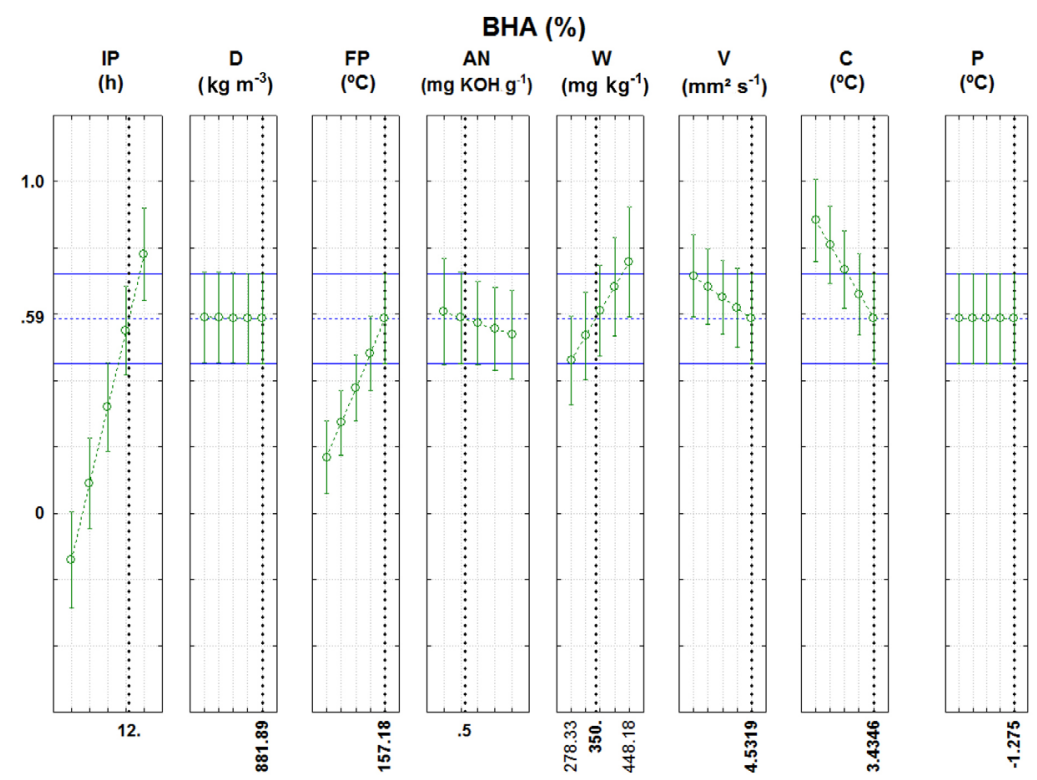

Figure 5. Biodiesel parameters optimization for $B H A$

mass needed for the parameters to meet the established standards is $0.59 \%$ by mass.

The optimization for BHT with the same parameter values (independent variables) found in the BHA minimization mass is shown in Figure 6. We can see that the smallest BHT mass necessary for the parameters, induction period, flash point, water content, cloud point, acid number and viscosity are within the norms established by Brazilian legislation ${ }^{19,33}$ is $0.64 \%$ by mass. This value is only 1.08 times greater than the value $(0.59 \%)$ found in the optimization by minimizing the BHA mass.

According to Figures 5 and 6, the BHA had a lower mass necessary to keep the analyzed parameters within specification, when compared to the value of $0.64 \%$ obtained by the equation that describes the BHT mass.

Both BHA and BHT have a single hydroxyl group in their molecules and are sterically hindered phenolic groups with tertiary butyl groups in position ortho to the hydroxyl group. ${ }^{48}$ BHT has a greater steric impediment than BHA and, as a consequence, when donating hydrogen to restore the free radical formed by the biodiesel oxidation, when it becomes a free radical, will show a lesser tendency to propagate the oxidation reaction when compared to BHA. However, as each molecule of the antioxidants used is capable of donating only one hydrogen to prevent or delay the biodiesel esters oxidation reaction, both will exhibit similar antioxidant behavior.

According to Silva et al.,${ }^{18}$ the thermogravimetric analysis (TG) of BHA and BHT, showed for BHA a loss of mass of $25.99 \%$ in the first event, at $173.18{ }^{\circ} \mathrm{C}$, and $73.94 \%$ at $212.78{ }^{\circ} \mathrm{C}$, while BHT showed a mass loss of $38.07 \%$ in the first event at $196.59{ }^{\circ} \mathrm{C}$ and $61.08 \%$ at $225.48{ }^{\circ} \mathrm{C}$. This analysis indicated that the antioxidants used do not undergo thermal decomposition at the temperature of $110{ }^{\circ} \mathrm{C}$ used in the oxidative stability test by the accelerated heating method via Rancimat ${ }^{\circledR}$. In addition, according to the same authors, at the beginning of BHT and BHA thermal decomposition, temperatures were approximately $112{ }^{\circ} \mathrm{C}$ and $121{ }^{\circ} \mathrm{C}$. Therefore, the antioxidants thermal decomposition was not verified at the test temperature, and is not responsible for the small power difference found between them.

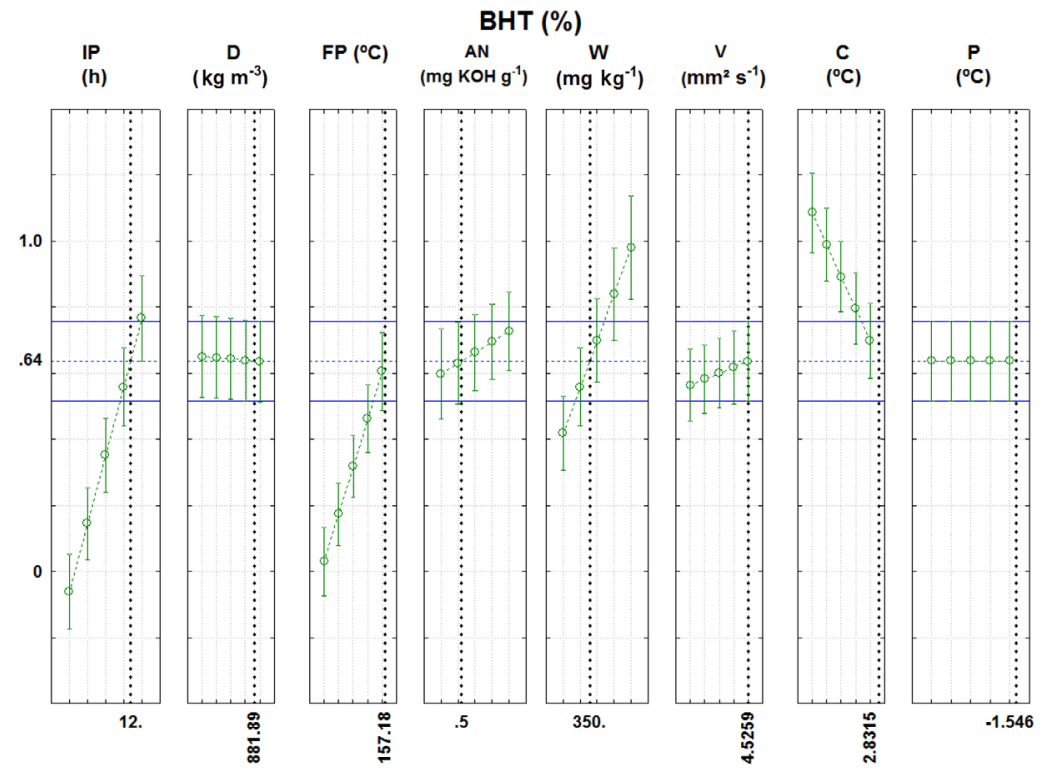

Figure 6. Biodiesel parameters optimization for BHT 


\section{CONCLUSIONS}

Establishing predictive mathematical models, which use the physical-chemical parameters normally analyzed in the manufacturing industries, proved to be of great use in assessing the amount of antioxidant BHA or BHT that must be added to biodiesel, so that it reaches, at least, the minimum value of the induction period established by the regulatory agencies, before being commercialized. In addition, it allows to diminish possible excesses in the use of the additive reducing the biodiesel production cost.

\section{ACKNOWLEDGMENTS}

The authors would like to thank the State University of Londrina (UEL) and the Research and Analysis Laboratory of Fuels (LPAC).

\section{REFERENCES}

1. Galvan, D.; Chendynski, L. T.; Mantovani, A. C.; Quadri, M.; Killner, M.; Cremasco, H.; Borsato, D.; J. Braz. Chem. Soc. 2020, 31, 313.

2. Chendynski, L. T.; Cordeiro, T.; Messias, G. B.; Mantovani, A. C. G.; Spacino, K. R.; Zeraik, M. L.; Borsato, D.; Fuel 2020, 261, 116379.

3. OPEC; World Oil Outlook; Organization of the Petroleum Exportin Countries: Vienna, Austria, 2016.

4. Gebremariam, S. N.; Marchetti, J. M.; Energy Convers. Manage. 2018, 168,74 .

5. Ma, F.; Hanna, M. A.; Bioresour. Technol. 1999, 70, 1.

6. Brasil; Produção de biodiesel atinge 452 milhões de litros, maior volume nos últimos dez anos. Ministério de Minas e Energia, 2018.

7. Orives, J. R.; Galvan, D.; Pereira, J. L.; Coppo, R. L.; Borsato, D.; J. Am. Oil Chem. Soc. 2014, 91, 1805.

8. Knothe, G.; Steidley, K. R.; Fuel Process. Technol. 2018, 177, 75.

9. Kumar, N.; Fuel 2017, 190, 328.

10. Orives, J. R.; Galvan, D.; Coppo, R. L.; Rodrigues, C. H. F.; Angilelli, K. G.; Borsato, D.; Energy Convers. Manage. 2014, 79, 398.

11. Almeida, V. F. de; García-Moreno, P. J.; Guadix, A.; Guadix, E. M.; Fuel Process. Technol. 2015, 133, 152.

12. Mantovani, A. C. G.; Chendynski, L. T.; Salviato, A.; Borsato, D.; Santana, V. T.; Di Mauro, E.; Fuel 2018, 224, 255.

13. Chendynski, L. T.; Mantovani, A. C. G.; Savada, F. Y.; Messias, G. B.; Santana, V. T.; Salviato, A.; Di Mauro, E.; Borsato, D.; Fuel 2019, 242, 316.

14. Spacino, K.; Mantovani, A. C.; Marcheafave, G.; Canesin, E.; Borsato, D.; J. Braz. Chem. Soc. 2020.

15. Spacino, K.; Cremasco, H.; Angilelli, K.; Mantovani, A. C.; Borsato, D.; Quim. Nova 2020.

16. Maia, E. C. R.; Borsato, D.; Moreira, I.; Spacino, K. R.; Rodrigues, P. R. P.; Gallina, A. L.; Fuel Process. Technol. 2011, 92, 1750.

17. Borsato, D.; Dall'Antonia, L. H.; Guedes, C. L. B.; Maia, E. C. R.; Freitas, H. R. de; Moreira, I.; Spacino, K. R.; Quim. Nova 2010, 33, 1726.

18. Silva, E. T.; Spacino, K. R.; Silva, L. R. C.; Romagnoli, É. S.; Angilelli, K. G.; Borsato, D.; Acta Sci., Technol. 2018, 40

19. Brasil; RESOLUÇÃO No 798, DE $1^{\circ}$ DE AGOSTO DE 2019 Regulamento Técnico ANP N³/2014 2019.

20. Buosi, G. M.; da Silva, E. T.; Spacino, K.; Silva, L. R. C.; Ferreira, B. A. D.; Borsato, D.; Fuel 2016, 181, 759.

21. Krisnangkura, K.; Yimsuwan, T.; Pairintra, R.; Fuel 2006, 85, 107.

22. Pham, M. T.; Hoang, A. T.; Le, A. T.; Al-Tawaha, A. R. M. S.; Dong, V. H.; Le, V. V.; Int. J. Technol. 2018, 9, 1015.
23. Alviso, D.; Artana, G.; Duriez, T.; Fuel 2020, 264, 116844.

24. Mairizal, A. Q.; Awad, S.; Priadi, C. R.; Hartono, D. M.; Moersidik, S. S.; Tazerout, M.; Andres, Y.; Renewable Energy 2020, 145, 375.

25. ASTM D4052-18a, Standard Test Method for Density, Relative Density, and API Gravity of Liquids by Digital Density Meter, ASTM International, West Conshohocken, PA, 2018, www.astm.org.

26. ASTM D93-20, Standard Test Methods for Flash Point by PenskyMartens Closed Cup Tester, ASTM International, West Conshohocken, PA, 2020, www.astm.org.

27. ASTM D445-21, Standard Test Method for Kinematic Viscosity of Transparent and Opaque Liquids (and Calculation of Dynamic Viscosity), ASTM International, West Conshohocken, PA, 2021, www. astm.org.

28. ASTM D664-18e2, Standard Test Method for Acid Number of Petroleum Products by Potentiometric Titration, ASTM International, West Conshohocken, PA, 2018, www.astm.org.

29. ASTM D6304-20, Standard Test Method for Determination of Water in Petroleum Products, Lubricating Oils, and Additives by Coulometric Karl Fischer Titration, ASTM International, West Conshohocken, PA, 2020, www.astm.org.

30. ASTM D2500-17a, Standard Test Method for Cloud Point of Petroleum Products and Liquid Fuels, ASTM International, West Conshohocken, PA, 2017, www.astm.org.

31. European Committee for Standardization; EN 14112: Determination of oxidation stability (accelerated oxidation test), 2016.

32. Statistica 13.1, StatSoft.

33. Brasil; Resolução ANP No 45, DE 25 DE AGOSTO DE 2014 - Ficam estabelecidas, por meio da presente Resolução, a especificação do biodiesel contida no Regulamento Técnico ANP n ${ }^{\circ}$ 3/2014 e as obrigações quanto ao controle da qualidade a serem atendidas pelos diversos 2014

34. Mishra, S.; Bukkarapu, K. R.; Krishnasamy, A.; Fuel 2021, 285, 119056.

35. Ramadhas, A.; Jayaraj, S.; Muraleedharan, C.; Fuel 2005, 84, 335.

36. Lacoste, F.; Lagardere, L.; Eur. J. Lipid Sci. Technol. 2003, 105, 149.

37. Fregolente, P. B. L.; Fregolente, L. V.; Wolf Maciel, M. R.; J. Chem. Eng. Data 2012, 57, 1817.

38. Huang, Y.; Li, F.; Bao, G.; Wang, W.; Wang, H.; J. Chem. Eng. Data 2020, 65, 2476

39. Wang, Q.; Pan, X.; Lin, C.; Ma, X.; Cao, S.; Ni, Y.; Chem. Eng. J. 2020, $396,125341$.

40. European Committee for Standardization; EN 14214: Automotive fuels. Fatty acid methyl esters (FAME) for diesel engines-Requirements and test methods, 2019.

41. Shieh, C.-J.; Liao, H.-F.; Lee, C.-C.; Bioresour. Technol. 2003, 88, 103.

42. Correia, I. A. S.; Borsato, D.; Savada, F. Y.; Pauli, E. D.; Mantovani, A. C. G.; Cremasco, H.; Chendynski, L. T.; Renewable Energy 2020, 160, 288.

43. Varatharajan, K.; Pushparani, D. S.; Renewable Sustainable Energy Rev. 2018, 82, 2017.

44. Shahabuddin, M.; Kalam, M. A.; Masjuki, H. H.; Bhuiya, M. M. K.; Mofijur, M.; Energy 2012, 44, 616.

45. Leng, L.; Li, W.; Li, H.; Jiang, S.; Zhou, W.; Energy Fuels 2020, 34, 10364.

46. Atadashi, I. M.; Aroua, M. K.; Abdul Aziz, A. R.; Sulaiman, N. M. N.; Renewable Sustainable Energy Rev. 2012, 16, 3456.

47. Gonçalves, H. L.; Bogalhos Lucente Fregolente, P.; Wolf Maciel, M. R.; Fregolente, L. V.; Sep. Sci. Technol. 2021, 56, 374.

48. Bruice, P. Y.; Química Orgânica, $4^{\text {th }}$ ed., Pearson Prentice Hall: São Paulo, 2006 